NASA Technical Memorandum 87196

Experiments for the Determination of Convective Diffusion Heat/Mass Transfer to Burner Rig Test Targets Comparable in Size to Jet Stream Diameter

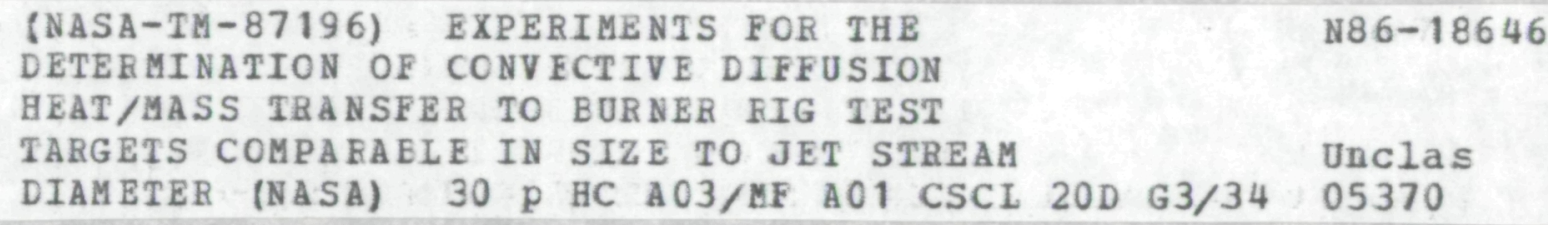

Gilbert J. Santoro and Süleyman A. Gökoğlu

Lewis Research Center

Cleveland, Ohio

Prepared for the

1986 Winter Annual Meeting of the American Society of Mechanical Engineers

Anaheim, California, November 30-December 5, 1986






\title{
EXPERIMENTS FOR THE DETERMINATION OF CONVECTIVE DIFFUSION HEAT/MASS \\ TRANSFER TO BURNER RIG TEST TARGETS COMPARABLE IN SIZE TO JET
}

\section{STREAM DIAMETER}

\author{
Gilbert J. Santoro and Süleyman A. Gökoğlul \\ National Aeronautics and Space Administration \\ Lewis Research Center \\ Cleveland, Ohto 44135
}

\section{ABSTRACT}

The application of a recently formulated vapor transport theory to predict deposition rates of corrosive salts from alkali-seeded combustion gases of a small-capacity, high-velocity, atmospheric-pressure burner rig was hampered by the relatively large dimensions of the cylindrical deposit collector compared to the diameter of the combustion gas stream. The relative dimensions lead to a highly nonadiabatic combustion gas flow around the collector and necessitated two series of experiments. In the first series, mass transfer coefficlents were determined by utflizing the naphthalene sublimation technique. The second series of experiments determined the dilution effect on the sodium species concentrations due to the entrainment of ambient air. This second series involved the measurement of the temperature variation along the surface of the collector under steady state conditions. Vapor deposition rates were determined exploiting this information and the results were found to compare favorably with experimentally obtained rates. INTRODUCTION

Accelerated blade and vane fallures can occur in the hot section of gas turbine engines due to the deposition of corrosive salts resulting from trace impurities in the combustion gases (hot corrosion). This problem prompted the investigation of the deposition rates occurring on internally air-cooled,

\footnotetext{
TCase Western Reserve University, Department of Mechanical and Aerospace Engineering, Cleveland, Ohio 44106 and NASA Resident Research Associate.
} 
inert, cylindrical collectors in the cross stream of the combustion products of a small-capacity, high-velocity, atmospheric-pressure-burner rig seeded with sodium salts $(\underline{1}-\underline{3})$.

Our intention was to compare the measured vapor transport deposition rates with a recently formulated comprehensive chemically frozen boundary layer $(C F B L)$ vapor transport theory $(\underline{4}, \underline{5})$. The original procedure for introducing the contaminant into the burner rig consisted of air atomization of various sodium salt solutions into the combustor. This resulted in inertial impaction of solution droplets onto the collector, precluding our. intended comparison. To insure that the sodium species were entirely in the vapor phase in the combustor, a new procedure was adopted which involved physically mixing. a solution of sodium acetate in ethanol with jet A-l fuel in the cavity of the fuel nozzle and spraying this mixture through the fuel nozzle into the combustor. However, dimensional restraints of the experimental set-up required additional information because the size of the deposition: collector was large $(1.90 \mathrm{~cm}$ diameter by $1.27 \mathrm{~cm}$ high cylinder) relative to. the $2.54 \mathrm{~cm}$ diameter of the combustion gas jet stream. The minimum size of the collector is dictated by its internal air cooling feature which allows the collector temperature to be controlled anywhere from beyond the dew point temperature of sodium sulfațe down to $500{ }^{\circ} \mathrm{C}$ while maintaining a constant fuel-to-air ratio (constant flame temperature, and chemistry of the sodium species vapors). Were the collector totally immersed in the jet stream (a "perfect". cylinder in crossflow situation), the mass transfer coefficient would be readily calculable and the local dopant species concentration would be equal to that in the burner exit nozzle. The dimensional relationship however results in a highly nonadiabatic combustion gas flow and a nonuniform mainstream gas concentration around the collector due to the entrafinment of ambient air. Consequently the local thermodynamic and transport properties 
become angle dependent. This angular dependency necessitated additional experiments to provide the mass transfer coefficlent and the dilution effect of the dopant species in the mainstream as input to the CFBL theory.

A series of experiments to determine the mass transfer coefficient were performed utilizing the naphthalene sublimation technique. The dilution effect was ascertained by measuring the temperature variation along the surface of the collector under steady state conditions. The discharge coefficient of the burner exit nozzle was also determined to provide values of the jet approach velocities, 1.e., to obtain accurate Reynolds numbers. Finally, vapor deposition rates were measured and their values compared with those predicted by the CFBL theory. The analytical techniques employed in this application of the theory, utilizing the transport parameters derived from the experiments presented here, have been reported in detail elsewhere (6) and are only outlined in this report for completeness. The predicted. vapor deposition rates compared favorably with measured rates. NÖMENCLATURE

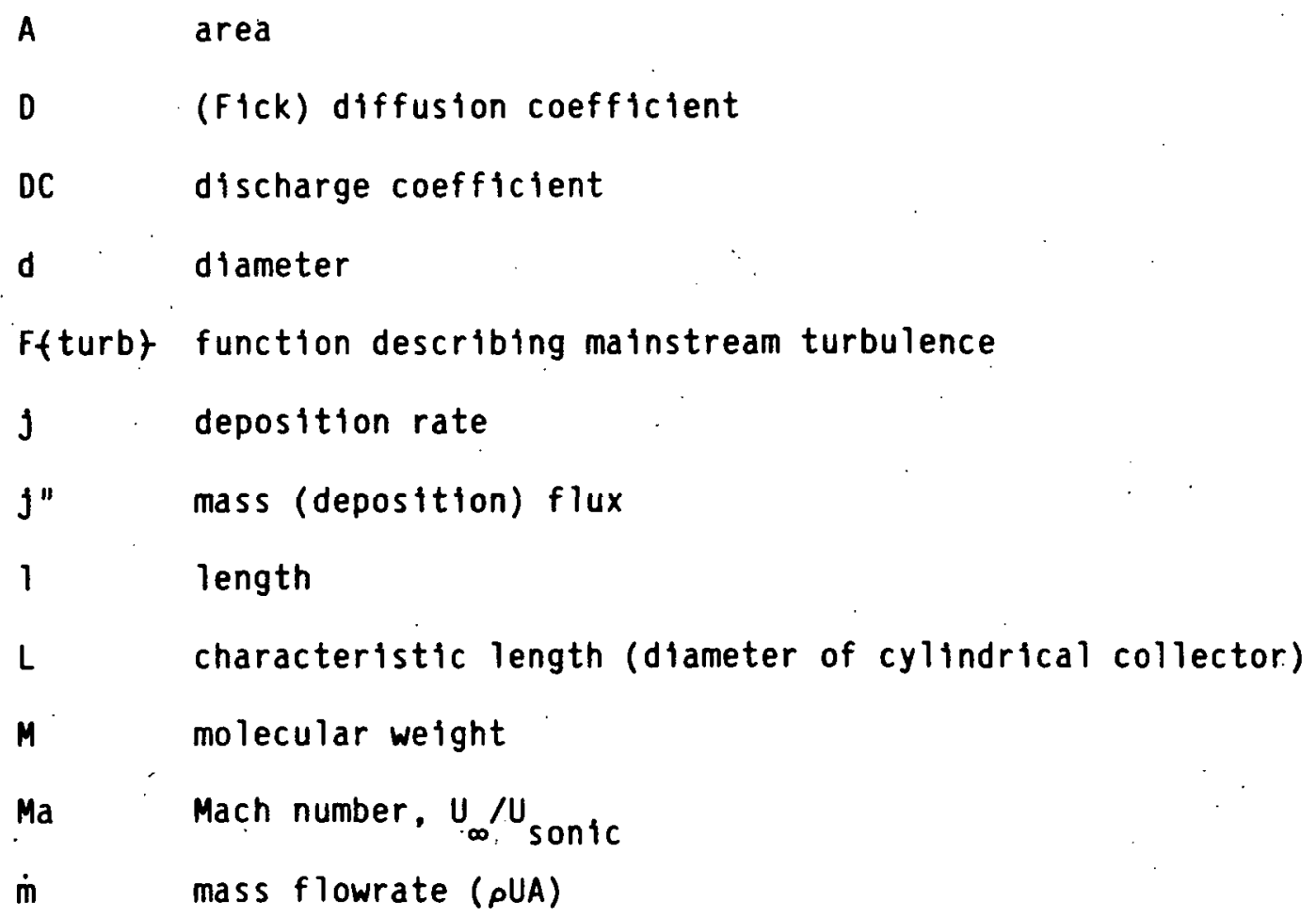




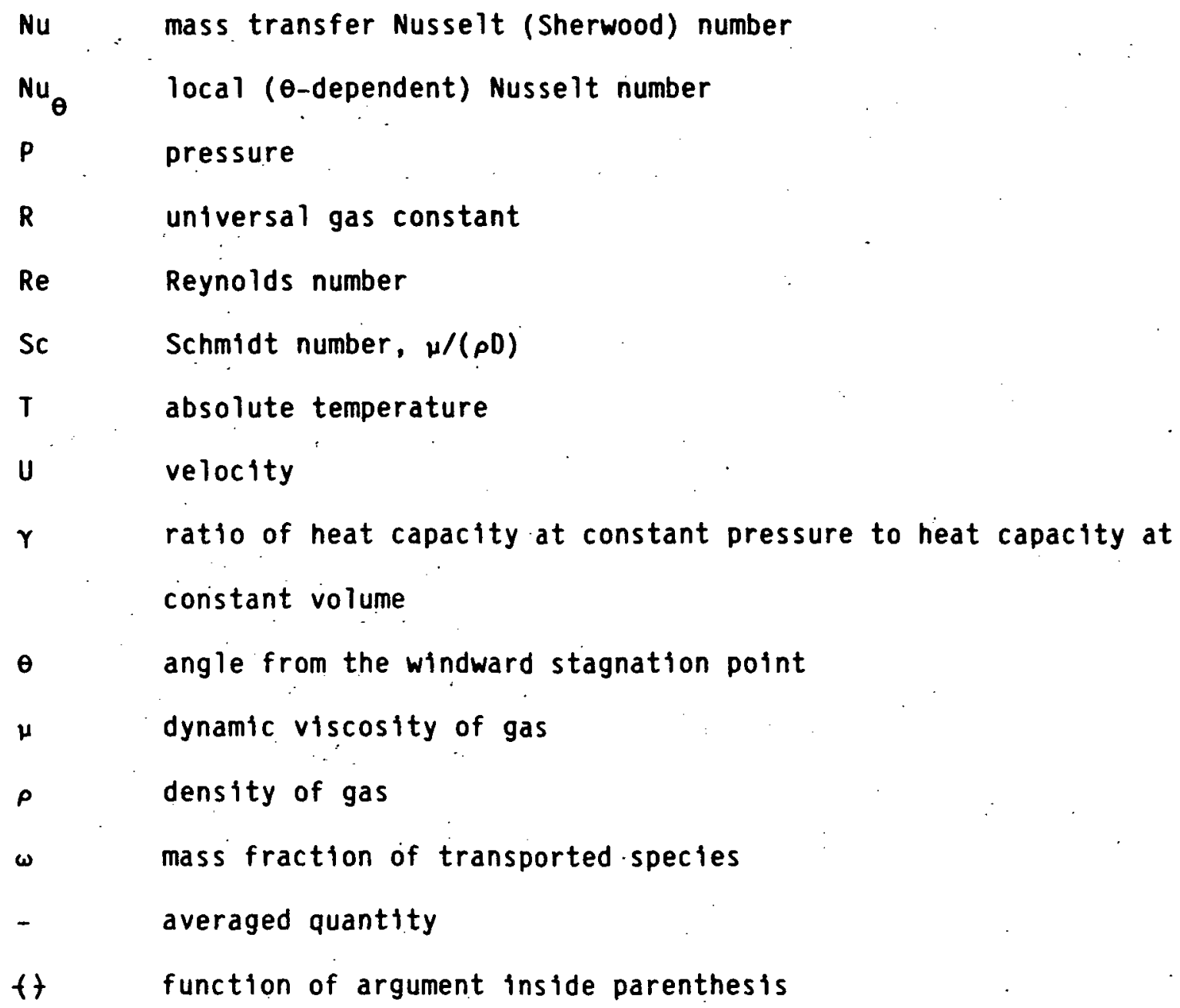


exit nozzle. Thése values were experimentally determined as a function of Reynolds number by measuring the differences between the stagnation and barometric pressures. A pitot tube and sensitive differential pressure ( \pm 2 psid) transducer were used for these measurements. Amblent pressure was recorded using a 0-20 psia transducer. The jet air stream temperature was measured with a sonic temperature probe. The pitot probe and the sonic temperature probe were attached one above the other on the vertical axis of a three axes remotely controlled slide mechanism. Figure 1 shows the dimensional configuration of the burner nozzle used in all the testing reported here. Equivalent aerodynamic conditions at flame temperature, (1.e., the same Reynolds number) required mass flow velocities of about $7 \mathrm{~g} / \mathrm{sec}$ under ambient temperature conditions, the lower sensitivity limit of our pressure difference measurements. The direct measurements of $\Delta P$ instead of the total pressure greatly reduced the uncertainty in calculating the jet exit velocities. Naphthalene Sublimation from Cylindrical Targets

Two sets of naphthalene sublimation experiments were conducted, one set in which the entire cast naphthalene target cylinder was exposed to the flow (full cylinder experiments) and another set in which all but a predetermined angular segment of the surface of the target cylinder was covered by cellophane tape. The exposed segment faced the jet stream (segmented cylinder experiments). In both series of experiments the cast naphthalene cylinders were enclosed in a small insulated tunnel attached to the exit nozzle of the burner so as to maintain near equal temperature between the jet stream and the ambient air, (within $0.5^{\circ} \mathrm{C}$ ). The full cylinder tests provided the data to determine the perimeter-averaged mass transfer coefficient, while the segmented cylinder tests yielded data to obtain the angular dependence of the mass transfer coefficlent by varying the angle of the exposed surface segment. 
Sublimation cylinder construction. The construction particulars and rigid tolerances duplicated those used by Sparrow et al., ( $($ ), except the overall dimensions were scaled to our requirements. The photograph in Fig. $2(a)$ shows the hardware used and Fig. 2(b) shows the test assembly with the cast naphthalene components in place. These components include the target element, the upper and lower guard sections which flank the target element and are themselves flanked by aluminum sections, and a base section for attachment to the rig. The entire assembly is held together by a center rod screwed into the base and fastened on top with a knurled nut. The overall length was intended to represent an infinitely long cylinder with respect to the jet air stream diameter from the burner rig. The cast target element dimensions duplicated those of the collectors employed in the deposition runs. Each guard element provided a naphthalene surface $1.90 \mathrm{~cm} \mathrm{high} \mathrm{by} 1.90 \mathrm{~cm}$ in diameter. The function of the guard elements was to eliminate the effects of axial interactions as discussed by sparrow et a 1.. (I).

Naphthalene casting procedures. A casting procedure described in Ref. 7 was followed to produce the naphthalene target and guard elements. A cylindrical brass sleeve was sipped over the respective element to serve as the outer boundary and create a mold cavity. Molten naphthalene was then poured into the cavity through a small hole in the upper face of the element, the pouring operation being facilitated by the use of a funnel. The air displaced from the cavity escaped through a second hole, also equipped with a funnel. Once the naphthalene had solidified, the element was readily separated from the sleeve by applying pressure from below. The inner surface of the sleeve had been lapped to a mirror finish and the finish of the exposed surface of the naphthalene was of comparable quality. Each completed cast cylinder was placed in its own storage contalner designed to minimize the 
inner air space and this limit the loss of naphthalene by sublimation during storage.

Sublimation testing procedures. Each test run was initiated with freshly cast naphthalene sections. The assembled cylinder was removed from its storage container immediately prior to insertion into a $20.3 \mathrm{~cm}$ diameter by $43.2 \mathrm{~cm}$ long insulated tunnel which was attached to the exit nozzle of the burner (see fig. 3). The cylinder was secured to a shaft extending through the wall of the tunnel, thus positioning the cylinder so that its target element was in the same position with respect to the burner nozzle as the collector would be in the deposition runs. Then the cast cylinder was shrouded by an outer concentric tube. The tunnel access door was fastened shut for the remainder of the operation and the desired airflow rate established. When the temperature of the air jet stream and ambient air in the tunnel was equilibrated, the shroud was lowered thereby exposing the . naphthalene to the airflow. Equilibration was considered established when the reading of a precision thermometer in the combustor of the burner was within $0.5{ }^{\circ} \mathrm{C}$ of that of an identical thermometer located in the tunnel. The : smallest scale reading of these thermometers was $0.2{ }^{\circ} \mathrm{C}$. The length of time the naphthalene was exposed to the airflow was limited so that the recession of the diameter of the target element would not exceed about 0.3 percent of the initial diameter, an amount which can be neglected. Thus the initial diameter was taken as the characteristic dimension in subsequent calculations. To accommodate this restriction, the interval of exposure varied from about $5 \mathrm{~min}$ for high flow rates (approximately $21 \mathrm{~g} / \mathrm{sec}$ ) and temperatures (approximately $25^{\circ} \mathrm{C}$ ) to about 30 min for low flow rates (approximately $7 \mathrm{~g} / \mathrm{sec}$ ) and temperatures (approximately $19^{\circ} \mathrm{C}$ ). Upon completion of the run the cylinder was removed from the tunnel, replaced into its storage container, and a fresh cylinder was placed into the 
tunnel. The process was repeated until four cylinders were exposed. The amount of mass transfer was determined by differencing the weighings made of the target section before and after the run. These weighings utflized an electronic balance with a smallest scale reading of $10^{-5} \mathrm{~g}$. Prior to actual sublimation testing, handling and storage weight losses of the target element were found to be within the precision of the balance, this includes the time spent within the shroud at maximum airflow and run time interval.

The testing procedures for the segmented cylinder experiments were equivalent to the full cylinder experiments except that prior to the initial weighing, the target section was carefully taped so as to expose only a windward angular segment of naphthalene surface. The exposed surface was centered on the stagnation point. The precise arc length of the exposed naphthalene was determined by carefully measuring its chord length with a caliper, where

$$
1_{\text {arc }}=\frac{\pi d}{180^{\circ}} \sin ^{-1}\left(\frac{1_{\text {chord }}}{d}\right)
$$

The reproductibility of the data was segment angle dependent, being..better for large angles. There were two contributing factors for this dependency. First, less weight loss could be permitted to occur at the smaller angles and still maintain the allowable radial thinning of the target. The second factor was due to the perturbation of the boundary layer flow around the target by the ends of the tape (at the tape end-naphthalene junctions). At the stagnation point we estimated the boundary layer thickness for a Reynolds number of $1.5 \times 10^{4}$. to be about a factor of five times the thickness of the tape (approximately $70 \mu \mathrm{m}$ ). This factor increases as a function of distance from the stagnation point because of the increasing thickness of the boundary layer. Thus, both the percentage of surface naphthalene affected by the tape edge perturbation and the percentage of the boundary layer perturbated, decreased 
with increase in the angle of the exposed naphthalene segment. We found we could gather acceptable data at segment angles of $\geq 40^{\circ}$.

\section{Angular Vartation of Collector Surface Temperature}

The entrainment of amblent air around the relatively large deposition collector resulted in cooling of the mainstream temperature and dilution of the sodium dopant specles concentrations. An indirect approach was taken to determine the angular variation of the dopant species concentration. Experiments were done to measure the angular variation of collector surface temperatures. The collectors were fabricated of materials with different thermal conductivities and exposed to different combustion gas temperatures under steady state conditions at different Reynolds numbers. When the normalized collector surface temperatures were plotted against angle for the burner operating range of interest, a "universal" curve emerged. The curve was independent of collector material, Reynolds number and approach gas temperature. We then assumed that the mainstream had the same normalized temperature distribution and that this distribution reflected the dopant species concentrations relative to their concentrations as they left the burner exit nozzle.

Surface temperature variation was measured for both $\mathrm{Pt}-20$ percent Rh collectors, normally utilized in the deposition runs, and alumina collectors of identical dimensions. The position of the collectors with respect to the exit nozzle of the burner were identical to the position of the deposition collectors in the deposttion runs. The internal cooling air feature of the collector was not utllized. The collector temperature was sensed by a thermocouple embedded in the wall just below the surface of the collector. The angular position of the thermocoupled collector was varied with respect to the direction of the jet stream by rotating the shaft supporting the collector. A scale attached to the shaft and a pointer attached to the table 
of the burner indicated the angle of rotation, the zero angle being the windward stagnation point where the thermocouple directly faced the combustion gases.

A typical run consisted of setting the collector at the zero angle, allowing the burner to come to thermal equilibrium at the desired burner pressure and fuel/air flows, measuring the combustion gas temperature with a sonic temperature probe, swinging the burner into position to heat the collector, recording the steady state collector temperature, rotating the collector to the next angle, recording its steady state temperature, continuing this procedure for all angles from 0 to $180^{\circ}$ in both directions, swinging the burner out of the heat position and finally rechecking the combustion gas temperature. The burner parameters were then changed (new mass flow and gas temperature) for the start of another run. In this way angular temperature variation data were gathered for Reynolds numbers from $1.4 \times 10^{4}$ to $1.8 \times 10^{4}$ and gas temperatures from 1700 to $2000 \mathrm{~K}$ on both the metallic and ceramic collectors.

Vapor Phase Deposition

The deposition runs were conducted as described by Santoro et al. (2), except for the method used to inject the sodium salt solutions into the combustor. In order to eliminate the deposition of molten droplets as occurred in the previous method, 1.e., to insure that the sodium species are entirely vaporized in the combustor, a dilute solution of sodium acetate in ethanol was pumped into the fuel nozzle cavity to be mixed there with the jet A-1 fuel. The salt solution pump was a diaphragm type whose stroke length and frequency and the back pressure on the system (fuel nozzle pressure) determined its delivery rate. The mixture of fuel and sodium acetate-alcohol solution was sprayed through the fuet nozzle, mixed with swirling preheated air $\left(140^{\circ} \mathrm{C}\right)$ and burned. The volume. flow ratio of alcohol to fuel was 0.05 . 
Figure 4 is a photograph of the detached back flange of the burner housing showing the fuel nozzle and the fuel and alcohol inlet ports. The salt-alcohol solution flow rate was determined by the rate of decrease of solution volume in its $500 \mathrm{ml}$ graduated cylinder reservolr. The smallest reading on the graduated cylinder was $5 \mathrm{ml}$.

Some of the sodium fed into the burner deposited as the acetate on the inner walls of the burner liner $(5.08 \mathrm{~cm}$ diameter) at its cooled end. Also a negligibly small amount was found as sodium sulfate on the hot end of the liner and on the throat of the exit nozzle. From chemical analyses of the deposit on the liner, we estimated that about 25 percent of the total sodium injected was extracted from the combustion gases, ylelding a corrected typical sodium concentration of $6 \mathrm{ppm}$ with respect to the air mass flow of $25 \mathrm{~g} / \mathrm{sec}$. Other typical operating parameters are: 30 min run times, Mach number of 0.3 , Reynolds number of $1.7 \times 10^{4}$, fuel to air mass flowrate ratio of 0.035 , and. combustion gas temperature of $1800 \mathrm{~K}$. The $\mathrm{Pt}-20$ percent $\mathrm{Rh}$ collector temperature was varfed from 600 to $900{ }^{\circ} \mathrm{C}$ by means of its internal air impingement cooling feature. The dimensions of the collector were $1.90 \mathrm{~cm}$ in diameter and $1.27 \mathrm{~cm}$ in length. The deposit on the collector in all cases was essentialiy sodium sulfate resulting from the excess presence of sulfur impurity available in the fuel $(0.02$ to 0.06 percent). Frequent cleaning of the combustor liner insured that salt deposit bulld-up would not become so thick as to shed the deposit back into the combustion gases as particles incapable of revaporizing during their short residence times in the combustor and large enough to inertially impact upon the collector. 


\section{REDUCTION OF THE DATA AND EXPERIMENTAL RESULTS}

\section{Discharge coefficient data reduction and results}

The discharge coefficient of the burner exit nozzle is defined as the ratio of the effective area of the jet nozzle through which gas with a uniform velocity profile passes to the geometric area, 1.e.,

$$
D C=\frac{A_{\text {eff }}}{A_{\text {nozzle }}}
$$

The isentropic jet expansion relationship can be applied at ambient condtions to obtain the jet exit velocity

$$
U_{\infty}=U_{\text {sontc }}\left\{\left[\left(1+\frac{\Delta P}{P_{\infty}}\right)^{\frac{(\gamma-1)}{\gamma}}-1\right] \frac{2}{\gamma-1}\right\}^{1 / 2}
$$

where $\Delta P=P_{0}-P_{\infty}$ and $U_{\text {sonic }}=(Y R T / M)^{1 / 2}$. For a known gas mass flow rate, $\dot{m}$, using the ideal gas law, the effective nozzle area is,

$$
A_{\text {eff }}=\frac{R T_{\infty}}{P_{\infty} M} \frac{\dot{m}}{U_{\infty}}
$$

We measured $\triangle P, P_{\infty}$ and $\dot{m}$ under ambient conditions and at equivalent aerodynamic conditions of interest at flame temperatures (same Reynolds numbers). Measuring $\Delta P$ instead of $P_{0}$ greatly reduced the experimental uncertainty as confirmed by an error analysis.

Figure 5 is a plot of the discharge coefficient as a function of Reynolds number. Data was accumulated at Reynolds numbers well above the range of immediate interest to the problem. Note that the Reynolds numbers are given with respect to the diameter of the throat of the burner exit nozzle. Thus the Reynolds number range of interest with respect to the nozzle $(2.0$ to $2.7) \times 10^{4}$ in Fig. 5 differs from that with respect to the cylinders used in the sublimation and deposition experiments $(1.5$ to 2.0$) \times 10^{4}$. 
Sublimation Data Reduction and Results

In the sublimation experiments the mass transfer coefficient was not affected by the entrainment of ambient air as its temperature and the temperature of the jet stream were kept to within $0.5^{\circ} \mathrm{C}$. Thus the sublimation of naphthalene from the target cylinder was dependent on the jet stream temperature.

The measured naphthalene weight change data from both the full and the segmented sublimation runs were reduced to their respective dimensionless average mass transfer coefficients as follows. In the basic mass fiux equation,

$$
f^{\prime \prime}=\frac{e D}{L} \cdot \overline{N u} \cdot \omega_{w}
$$

The following substitutions are made, $\omega_{w}=\left(P_{\text {naph }} / P_{\infty}\right)\left(M_{\text {naph }} / \bar{M}\right)$, $D=\mu /(\rho S C)$, and $L=d$ where $P_{\text {naph }}$ is the vapor pressure of naphthalene at the prevailing temperature, $M_{\text {naph }}$ is the molecular weight of naphthalene and $\bar{M}$ is the mean molecular weight of gas. Multiplying through by $A$, the area of exposed naphthalene, and rearranging yields,

$$
\overline{N u}=\frac{(j)(S C)\left(P_{\infty}\right)(\bar{M})(d)}{(A)(\mu)\left(P_{\text {naph }}\right)\left(M_{\text {naph }}\right)}
$$

where $(A)\left(J^{\prime \prime}\right)=j$ is the measured target weight change. In addition to $j$, the barometric pressure and amblent temperatures were recorded. $P_{\text {naph }}$ was obtained from the published tables ( $\underline{8}-\underline{11}$ ) at the measured ambient temperature.

The segmented cylinder naphthalene sublimation data collected within the Reynolds number range of the deposition experiments allowed the determination of the effect of mainstream turbulence. The detalls were presented by Gökoğlu and Santoro ( $(\underline{6})$. Within this Reynolds number range, it was found that mainstream turbulence did not affect heat and/or mass transfer rates. 
The experimental mass transfer coefficients were compared to correlations for cylinder-in-crossflow situations. Two correlations were used; the correlation by whitaker (12) for the full cylinder,

$$
\overline{N u}=\left(0.4 \operatorname{Re}^{1 / 2}+0.06 \operatorname{Re}^{2 / 3}\right) \mathrm{Sc}^{0.38}
$$

and the modified stagnation point Nusselt number describing the stagnation point region for the segmented cylinder ( 6 )

$$
\overline{N u}_{\theta}=N u_{0}\left\{1-\frac{1}{4}\left(\frac{\theta}{\left(\frac{\pi}{2}\right)}\right)^{3}\right\} \quad 0 \leq \theta \leq \frac{\pi}{2}
$$

where

$$
N u_{0}=1.14 \mathrm{Re}^{1 / 2} \mathrm{Sc}^{0.35}
$$

Recall from the experimental procedure section that the angular dependence of the mass transfer was derived from segmented cylinder sublimation experiments where arc lengths of the exposed naphthalene was expressed by their subtended angles. What was actually measured then was the average mass transfer over the angles of the exposed naphthalene. Thus the equation representing the angular relationship.

$$
N u_{\theta}=N u_{0}\left[1-\left(\frac{\theta}{\left(\frac{\pi}{2}\right)}\right)^{3}\right] \quad 0 \leq \theta \leq \frac{\pi}{2}
$$

must be integrated to yield the average values encompassing the segments of exposed naphthalene for comparison with the experimental data. The integration of Eq. (10) is Eq. (8).

The quality of data from full cylinder tests is better than from segmented cylinder tests because of the influence of the tape on the boundary layer flow as explained earlier: In fact the full cylinder data was so reproducible that the uncertainty was entirely due to the precision of the naphthalene temperature measurements. Figure 6 represents experimental results from scme of the sublimation runs, where the mass transfer Nusselt number is given as a 
function of Reynolds number for full and segmented $\left(\theta=50^{\circ}\right)$ cylinders. Also shown are the correlation equations, Eq. (7) and (8). In the Reynolds number range of the deposition experiments $\left(1.5 \times 10^{4} \leq \operatorname{Re} \leq 2.0 \times 10^{4}\right)$, the correlation and experimental data are in agreement, i.e., the "perfect" cylinder in crossflow assumption is applicable here in spite of the relatively large collector dimensions with respect to the jet stream diameter. Thus the aerodynamic structure inside the boundary layer was not altered by the entrainment phenomenon around the collector. At higher Reynolds numbers, Ffturbt given by

$$
\text { Ffturbt }=\frac{\overline{N u} \text { (experimental) }}{\overline{N u} \text { (correlation) }}
$$

becomes greater than unity as indicated by the divergence of the experimental and correlation curves.

\section{Angular Temperature Data Reduction and Results}

From the angular surface temperature measurements on metalitc and ceramic cylinders exposed to the combustion gases of the burner rig, a normalized surface temperature distribution was derived that, within the burner operating range of interest, was found to be independent of combustion gas temperature, Reynolds number or collector conductivity. We assumed the same distribution describes the gas temperature variation around the collector, 1.e.,

$$
\left[\frac{T f \theta t-T_{1}}{T_{0}-T_{1}}\right]_{\text {collector }}=\left[\frac{T_{f} \theta f-T_{1}}{T_{0}-T_{1}}\right]_{\text {gas }}
$$

With the sonic temperature probe we also measured the leeward $\left(T_{1}\right)$ and the windward $\left(T_{0}\right)$ stagnation point gas temperatures. The leeward stagnation point gas temperature was determined by positioning the sonic temperature probe at various distances downstream of the collector along the centerline and extrapolating their values to the leeward stagnation point. The measurement of $T_{0}$ (gas), of course, did not require the presence of the 
collector. Then Tf $\mathrm{T}$ (gas) in Eq. (12) was calculated at each angle. A properly reduced gas temperature distribution was in turn generated from the calculated Tfot (gas) values and set equal to the properly reduced mass fraction distribution of the sodium species via the heat/mass transfer analogy, assuming turbulent mixing

$$
\left[\frac{T f \theta t-T_{a m b}}{T_{0}-T_{a m b}}\right]_{g a s}=\left[\frac{\omega_{e} f \theta t}{\omega_{0}}\right]
$$

Equation (13) is plotted against $\theta$ in Fig. 7.

Deposition Rates Data Reduction and Results

The experimental data gleaned from the testing described in this report has provided all the information required to apply the CFBL vapor transport theory to the deposition rate data from our burner rig experiments. The analytical technique developed for this purpose has already been reported by Gökoğlu and Santoro ( $\underline{6})$ and includes the multicomponent nature of the problem by corisidering the dominant sodium carrying species and the thermal diffusion and variable property effects due to steep temperature gradients. In general, the procedure consisted of integrating the local mass transfer (deposition) flux equation with each term within the equation expressed by its angle and/or temperature dependency.

$$
\begin{aligned}
& J_{W}^{\prime \prime}=\frac{1}{2 \pi L} \int_{0}^{2 \pi} \rho_{e} t e^{t \theta t t} \cdot D_{e} f T e^{f \theta t t t} \cdot N u t \theta, T_{e} f \theta t t \cdot \omega_{e} f \theta t \cdot d \theta \\
& \equiv \frac{1}{L} \cdot\left(\overline{\rho_{e}{ }^{D} e^{N u_{\theta} \omega_{e}}}\right)
\end{aligned}
$$

Notice that an approach directed at obtaining the isolated effective mainstream concentrations, $\bar{\omega}_{e}$, and the isolated effective Nusselt number, $\overline{\mathrm{Nu}}_{\theta}$, etc., would not give the correct total deposition rate as the average of the product is not equal to the product of the averages, 1.e.,

$$
\frac{1}{L} \cdot\left(\overline{\rho_{e} \cdot D_{e} \cdot N u_{\theta} \cdot \omega_{e}}\right) \neq L \cdot \bar{\rho}_{e} \cdot \bar{D}_{e} \cdot \bar{N}_{u} \cdot \bar{\omega}_{e}
$$


The predicted deposition rates derived from the analytical technique described by Gökoğlu and Santoro (ㅁ) are compared with the experimental rates in Fig. 8. The experimental data were reduced to the following set of conditions: $M_{\infty}=0.3, R e=1.74 \times 10^{4}$, fuel-to-airflow rate $=0.035$, $T_{0}=1800 \mathrm{~K}$. The predicted band refers to 30 percent (lower curve) and 20 percent (higher curve) of total sodium fed into the system lost on the wall of the burner liner (estimated at 25 percent). The reduced net sodium concentration for $\mathrm{Fig} .8$ is about $5 \mathrm{ppm}$ with respect to the combustion gases. Excellent agreement is found between theory and experiment for the plateau region. The disagreement above the melting point of sodium sulfate $\left(884^{\circ} \mathrm{C}\right)$ has been found to be due to shear-driven molten deposit layer run-off from the smooth collector surface $(1,13)$ resulting in lower experimental values.

For the Reynolds number range of the deposition experiments, $(1.5-2.0) \times 10^{4}$, the windward $(-\pi / 2 \leq \theta \leq \pi / 2)$, fraction of the deposit is expected to be about 65 percent of the total deposit for an ideal cylinder in crossfiow. The windward fraction Reynolds number dependence for an ideal cylindrical target in crossflow is given in Fig. 9, which is a modified version of the deposit distribution figure presented by Gökoğlu and Rosner (14). Instead of the best fit curve used by these authors, we have substituted a curve based on Eq. (7) and (8), the rat10 of mass transport averaged over the windward area to the perimeter averaged mass transfer, 1.e., Windward Fraction $\cong \frac{1.14 \mathrm{Re}^{1 / 2}(0.75)(\mathrm{A} / 2)}{\left(0.4 \mathrm{Re}^{1 / 2}+0.06 \operatorname{Re}^{2 / 3}\right)(\mathrm{A})} \cong\left(0.94+0.14 \mathrm{Re}^{1 / 6}\right)^{-1}$ Equation (15) assumes that the effect of $S c$ is negligible on the ratio. This modification of the original figure affirms the suitability of the cubic decline relationship describing the angular dependence of mass transfer coefficient on the windward surface of a cylinder (Eq. (10)) to represent experimental heat/mass transfer data. Just as the total amount of deposit is 
affected by the dilution of the mainstream dopants due to the entrainment of amblent air, so is the distribution of the deposit on the surface of the target. The dilution causes the leeward $(\pi / 2 \leq \theta \leq 3 \pi / 2)$ mainstream concentration to be less than the windward concentration therefore an even higher percentage of the total deposit should be collected on the windward surface. For our experimental set-up the windward fraction is calculated to be 83 percent of the total deposit, a significant increase above the 65 percent value for the ideal crossflow situation given in Fig. 9. CONCLUDING REMARKS

Vapor deposition rates were experimentally determined on an internally air-impingement cooled cylindrical collector located in the crossflow of the sodium-seeded combustion gases of a small-capacity, high-velocity burner rig. However, the collector dimensions, by virtue of its internal cooling feature, were comparable to (although less than) the diameter of the jet stream of. the burner, causing entrainment of ambient air resulting in a highly nonadiabatic gas flow around the collector. To predict the vapor deposition rates for comparison with the test data gathered from this set-up, experiments were required to determine the angular variation of both the mass transfer coefficient and the concentration of the sodium species in the gases around the collector. These experiments have been described in detall. The predicted deposition rates were found to be in excellent agreement with experiment. Thus the CFBL vapor deposition theory has been successfully applied to a nonidealized experimental arrangement which incorporated the high velocity gas flows characteristic of gas turbine engines.

Additional information resulting from these experiments include the following findings: (a) The aerodynamic boundary layer structure was not affected by: the entrainment phenomenon, (b) The mainstream turbulence factor was unity within the Reynolds number range of the deposition test parameters, 
(c) The mainstream turbulence factor could be represented by a single curve for both segmented and full cylinder data, (d) The cublc decline relationship expressing the angle dependence of the mass transfer coefficient proved suitable for our data and the experimental data of other authors, (e) It is predicted that not only the amount of deposit but the deposit distribution on the collector should be significantly altered by the dilution of the mainstream sodium species, therefore, the windward fraction of the deposit should be larger on our cylinders than on cylindrical targets totally immersed in the combustion gases.

\section{ACKNOWLEDGMENTS}

The authors take pleasure in expressing their appreciation to Professor E.M. Sparrow of the University of Minnesota, Dept. of Mechanical Engineering, for providing us with detailed information on the construction and experimental procedures of the naphthalene sublimation cylinder.

\section{REFERENCES}

1. Santoro, G.J., et a1, "Experimental and Theoretical Deposition Rates From Sait-seeded Combustion Gases of a Mach 0.3 Burner Rig," NASA TP-2225, 1984.

2. Santoro, G.J., et al, "Deposition of $\mathrm{Na}_{2} \mathrm{SO}_{4}$ from Salt-Seeded Combustion Gases of a High Velocity Burner Rig," High Temperature Corrosion in Energy Systems, M.F. Rothman, Ed., TMS-AIME Publịcations, 1985, pp. $417-434$.

3. Gökoğlu, S.A., "Experimental Verification of Vapor Deposition Model in Mach 0.3 Burner Rigs," Turbine Engine Hot Section Technology 1984, NASA CP-2339, 1984, Pp. 110-121.

4. Rosner, D.E, et a 1: "Chemically Frozen Multicomponent Boundary Layer Theory of Salt and/or Ash Deposition Rates from Combustion Gases," Combustion Science and Technology, Vol. 20, No. 3/4, 1979, pp. 87-106. 
5. Gökoğlu, S.A., Chen, B.K., and Rosner, D.E., "Computer Program for the Calculation of Multicomponent Convective Oiffusion Deposition Rates from Chemically Frozen Boundary Layer Theory," NASA CR-168329, 1984.

6. Gökoğlu, S.A. and Santoro, G.J., "Determination of Convective Diffusion Heat/Mass Transfer Rates to Burner Rig Test Targets Comparable in Size to Cross-Stream Jet Diameter." Submitted to the ASME 31 st International Gas Turbine Conference, Dusseldorf, Germany, June 1986.

7. Sparrow, E.M., Stah1, T.J., and Traub, P., "Heat Transfer Adjacent to the Attached End of a Cylinder in Crossflow," International Journal of Heat and Mass Transfer, Vol. 27, No. 2, Feb. 1984, pp. 233-242.

8. Ambrose, D., Lawrenson, I.J., and Sproke, C.H., "The Vapor Pressure of Naphthalene," Journal of Chemical Thermodynamics, Vol. 7, No. 12, Dec. 1975, pp. 1173-1176.

9. Camin, D.L., and Rossini, F.D., "Physical Properties of 14 American. Petroleum Institute Research Hydrocarbons, $C_{9}$ to $C_{15}$," Journal of Physical Chemistry, Vol. 59, No. 11, Nov. 1955, pp. 1173-1179.

10. Sogin, H.H., "Sublimation from Disks to Air Streams Flowing Normal to Their Surfaces," Transactions of the ASME, Vol. 80, 1958, pp. 67-67.

11. Vargaftik, N.B., Tables on the Thermophysical Properties of Liquids and Gases, Second ed., John Wiley, 1975, pp. 359.

12. Whitaker. S., Elementary Heat Transfer Analysis. Pergamon Press, 0xford, 1976. 
13. Rosner, D.E., Gïnes, D., and Nazih-Amous, N., "Aerodynamically Driven Condensate Layer Thickness Distributions on Isothermal Cylindrical Surfaces," Chemical Engineering Communications, Vol: 24, No. 4-6, 1983, pp. 275-287.

14. Gökoğlu, S.A., and Rosner, D.E., "Windward Fraction of the Total Mass or Heat Transport for Flow Past a Circular Cylinder," Aersol Sclence and Technology, Vo1. 2, No. 4, 1983, pp. 543-544. 


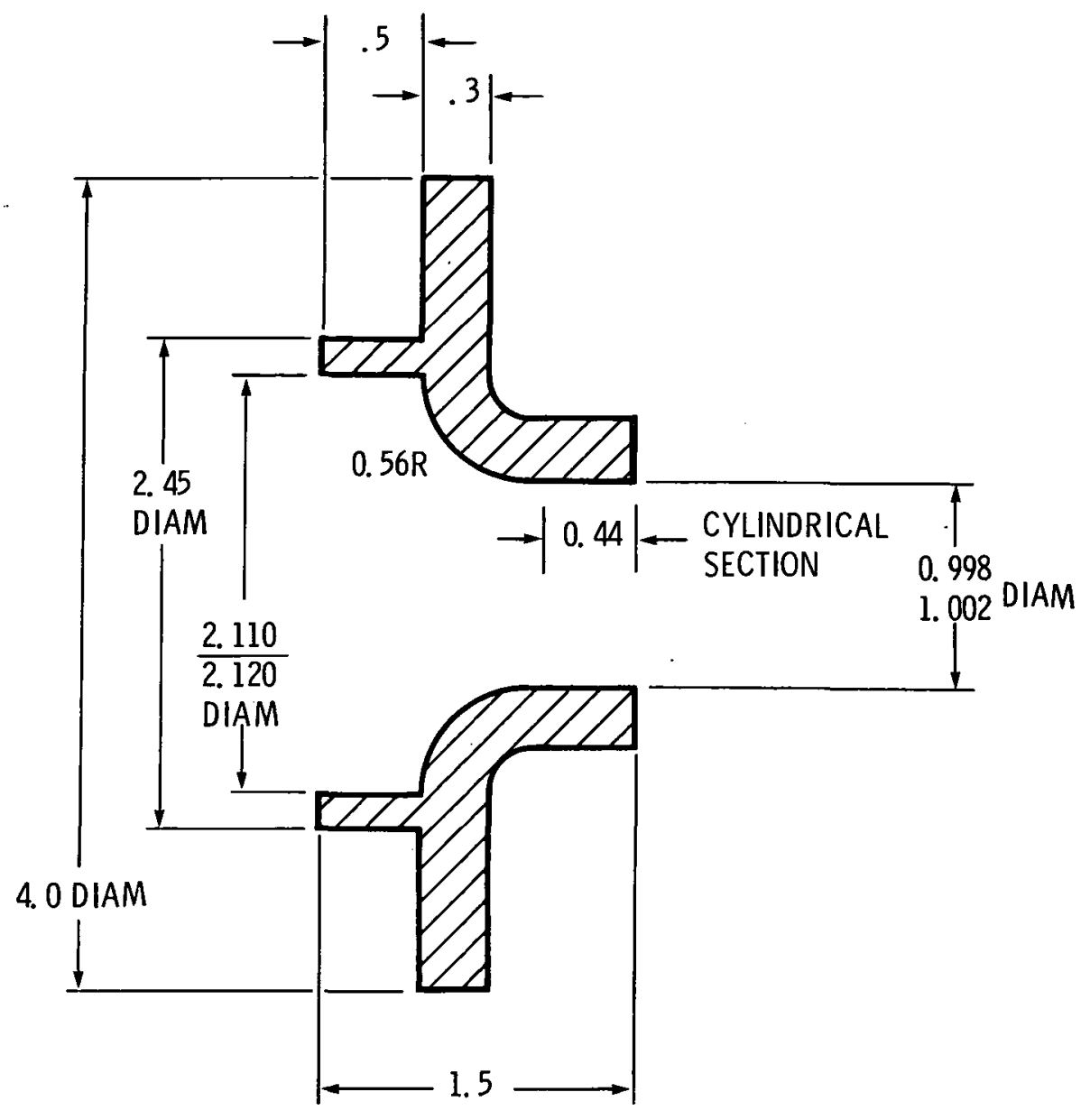

Figure 1. - Thin wall convergent burner exit nozzle used in all the experiments in this report. 


\section{ORICWML PAGE IS \\ OF POOR QUALITY}

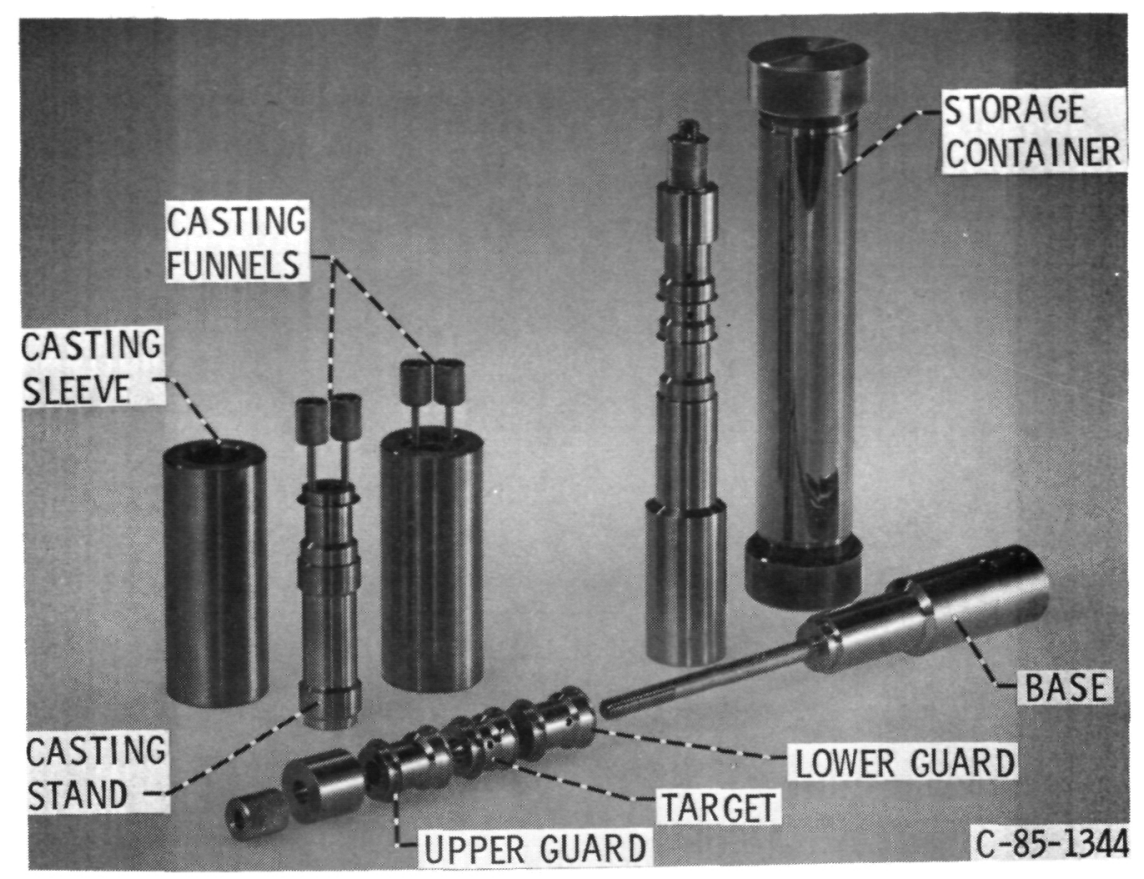

(a) Uncast cylinder components, casting hardware and storage container.

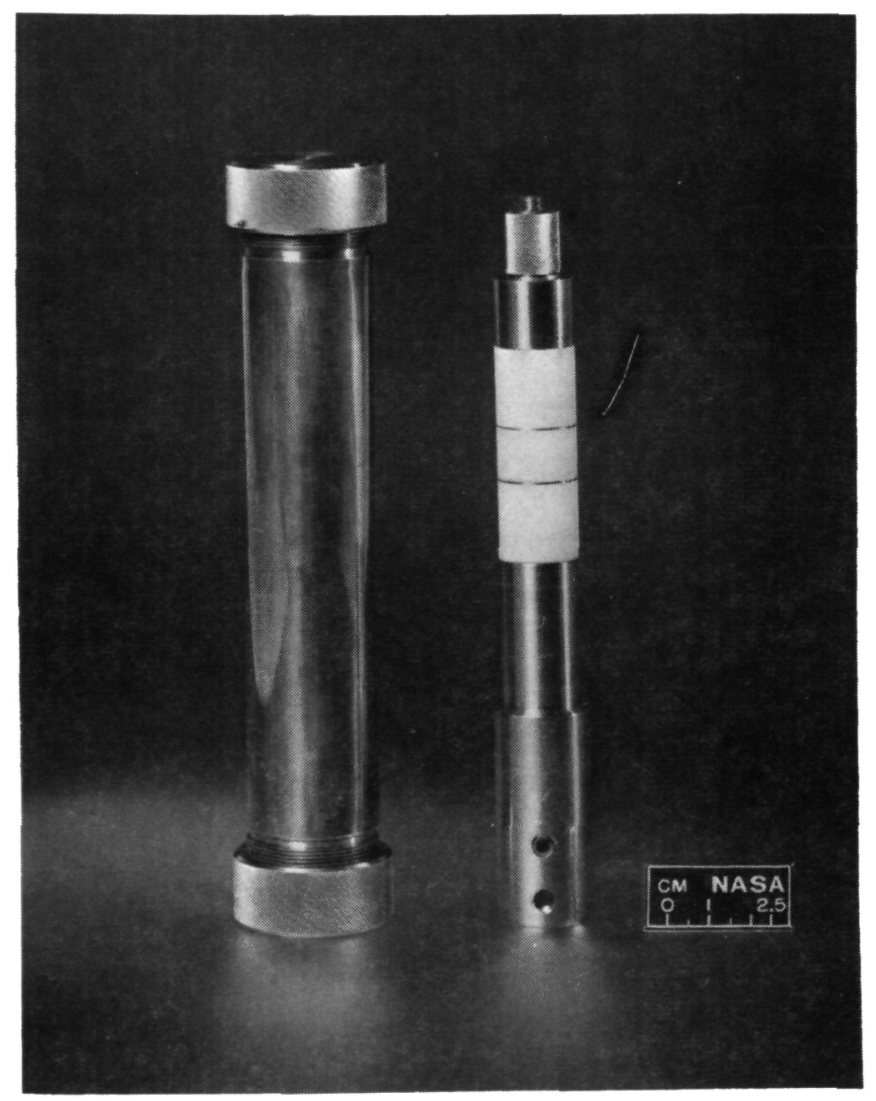

(b) Assembled cast cylinder and storage container.

Figure 2. - Naphthalene sublimation cylinder hardware. 




(a) Unshrouded naphthalene cast cylinder installed in the tunnel.

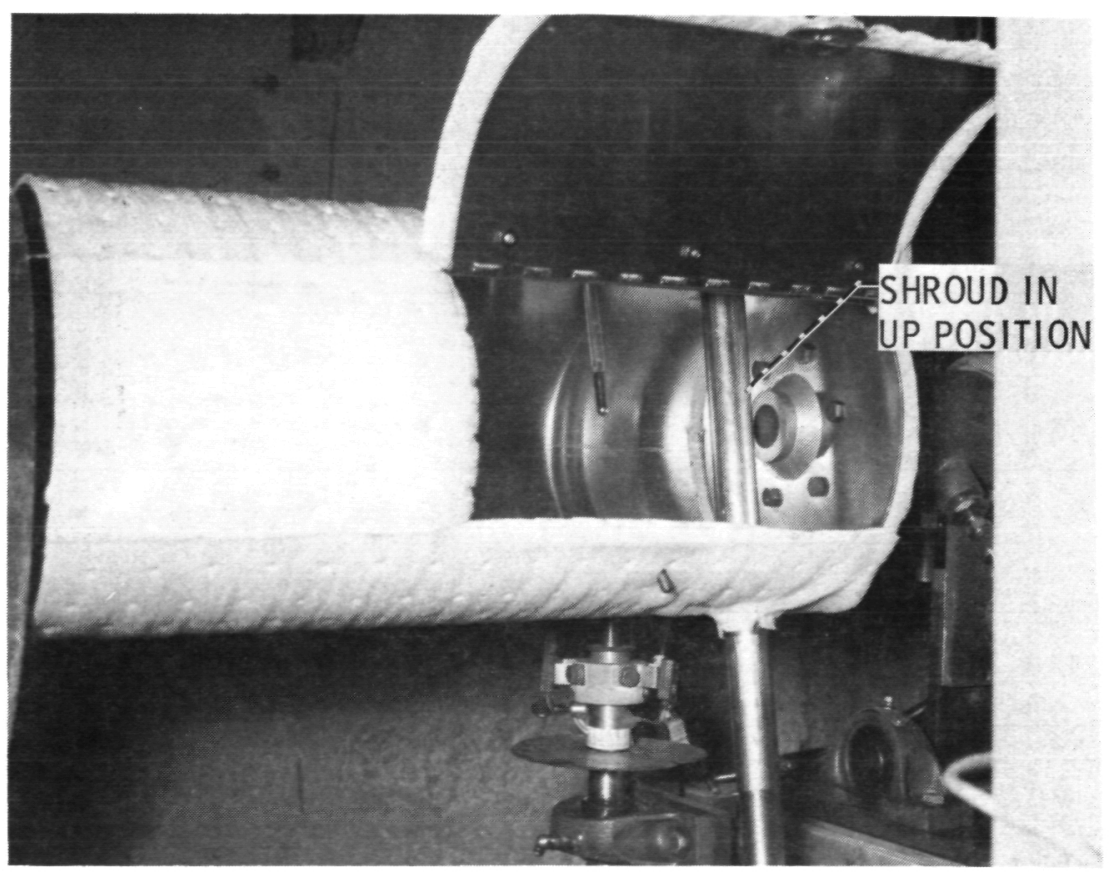

(b) Shroud in up position completely covering naphthalene cylinder.

Figure 3. - Insulated tunnel used in sublimation testing. 


\section{ORIGINAL PAGE 13 \\ OF POOR QUALITY}

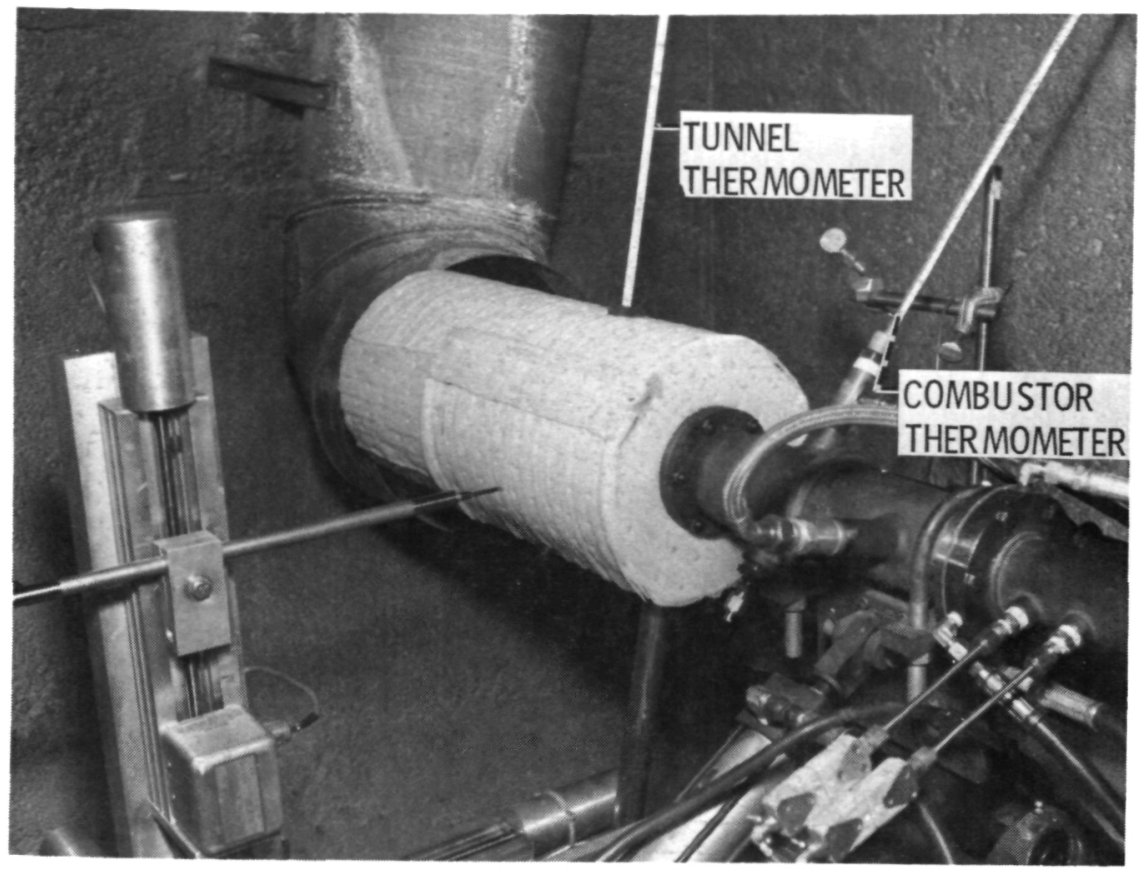

(c) View of tunnel attached to burner rig showing the tunnel and combustor ther mometers.

Figure 3. - Concluded.

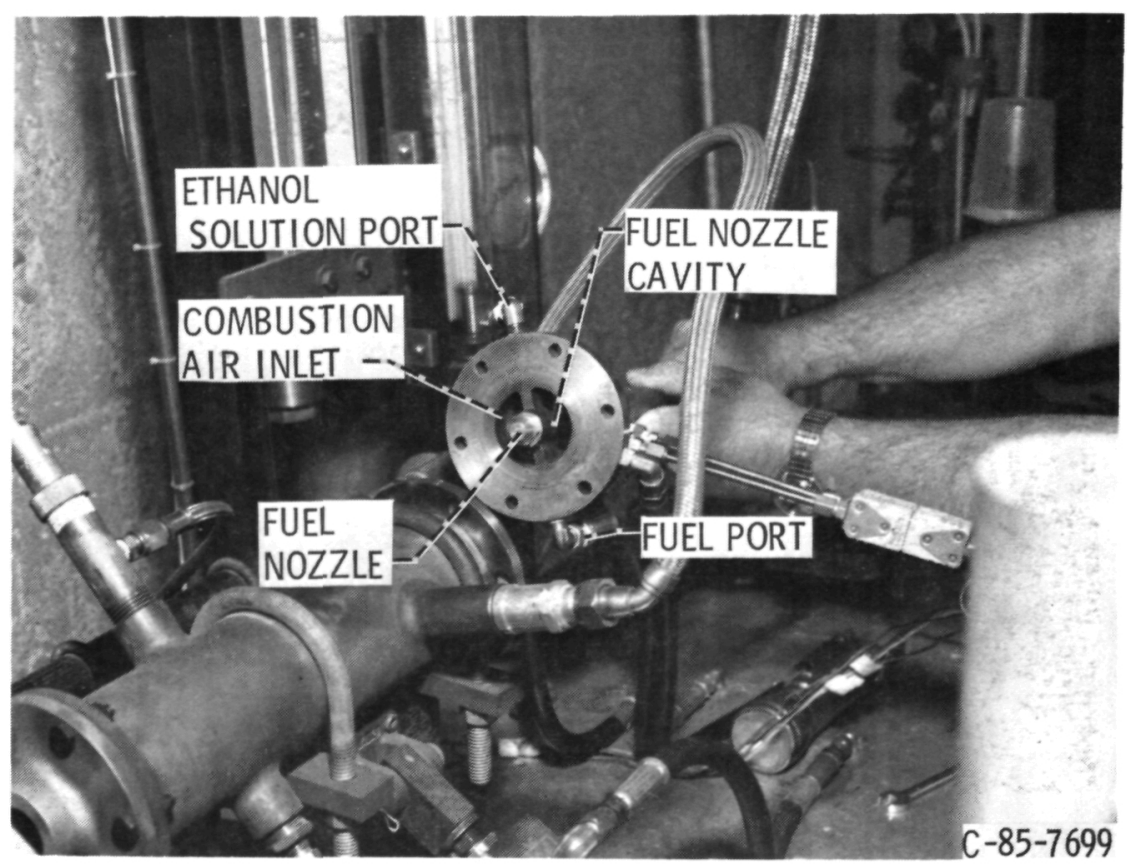

Figure 4. - Back flange of buiner rig detached from burner housing showing fuel and alcohol inlet ports, fuel nozzle and fuel nozzle cavity. 


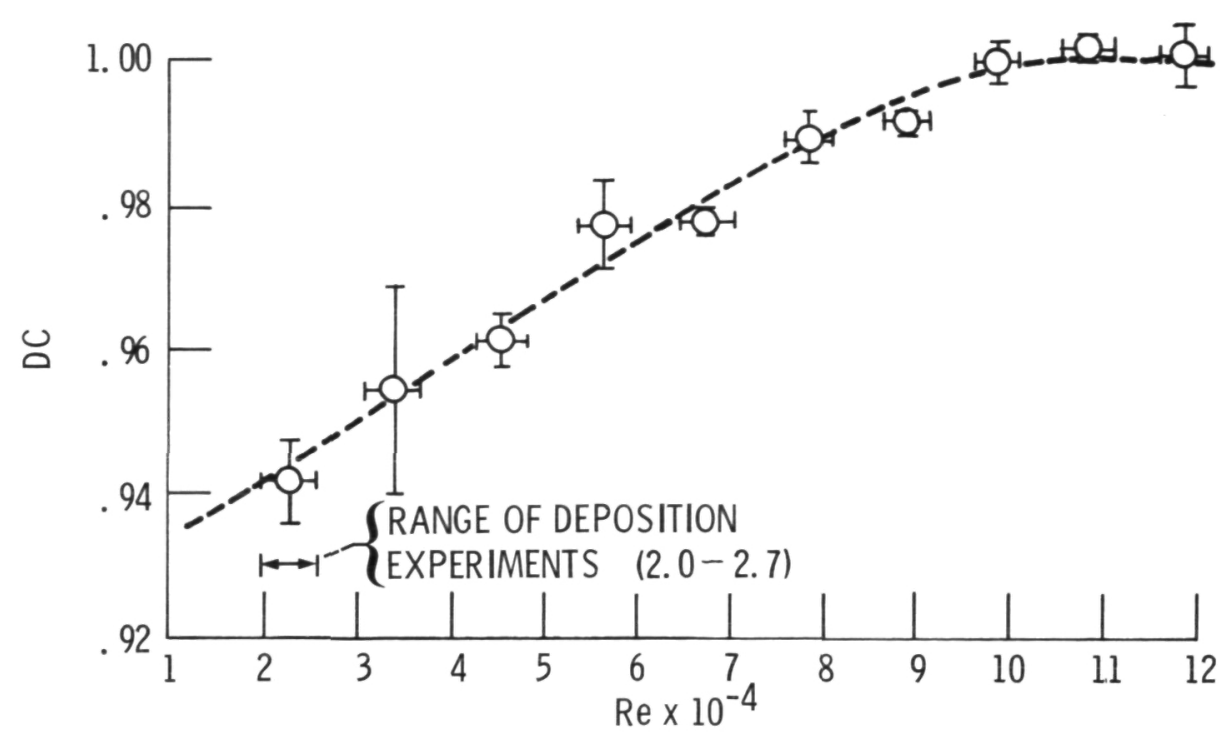

Figure 5. - Burner exit nozzle discharge coefficient as a function of Reynolds number based on nozzle diameter.

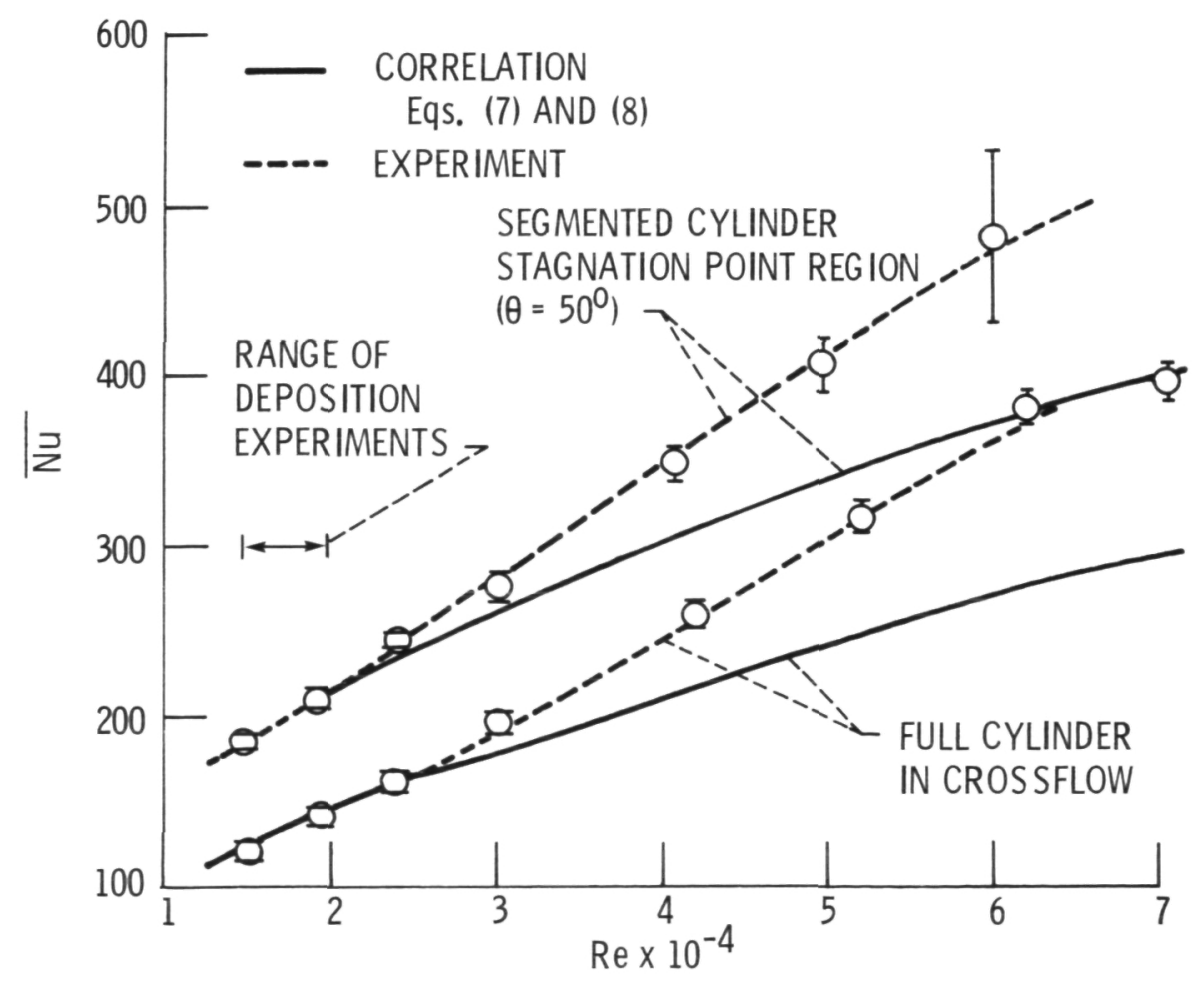

Figure 6。-Full and segmented cylinder mass transfer Nusselt number as a function of Reynolds number (based on cylinder diameter). 


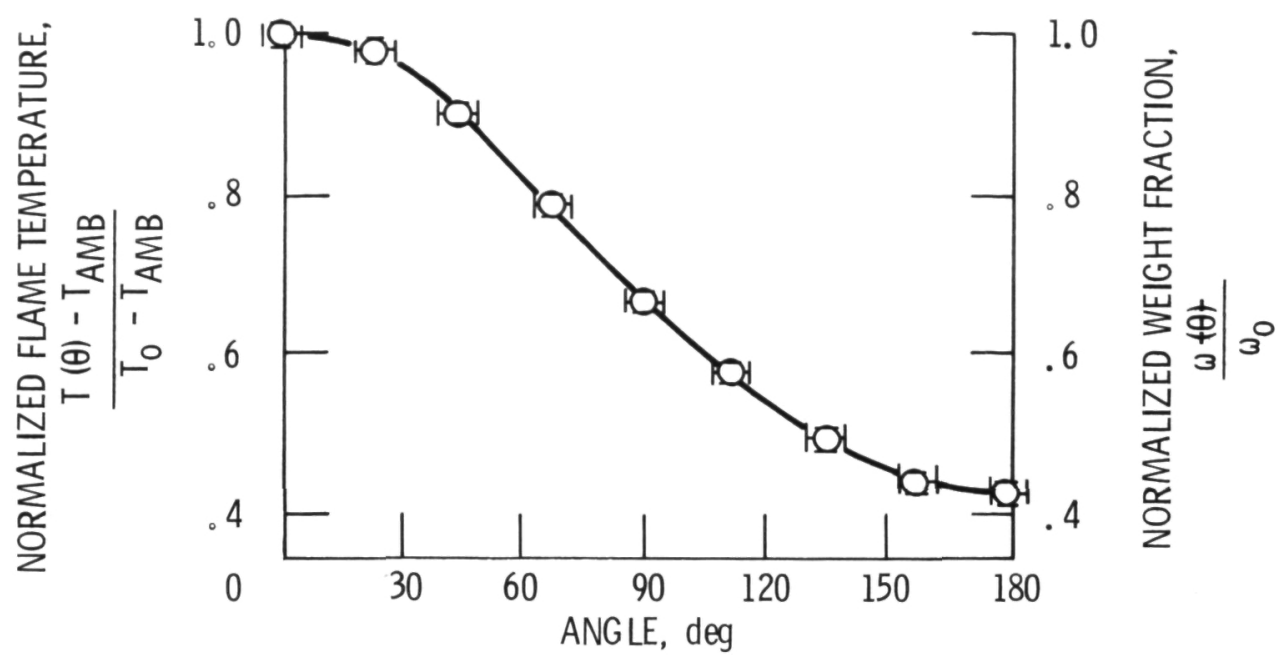

Figure 7. - Mainstream temperature and species mass fraction distribution around the collector as obtained from surface temperature measurements of collectors made of different materials for the range of operation of burner rig.

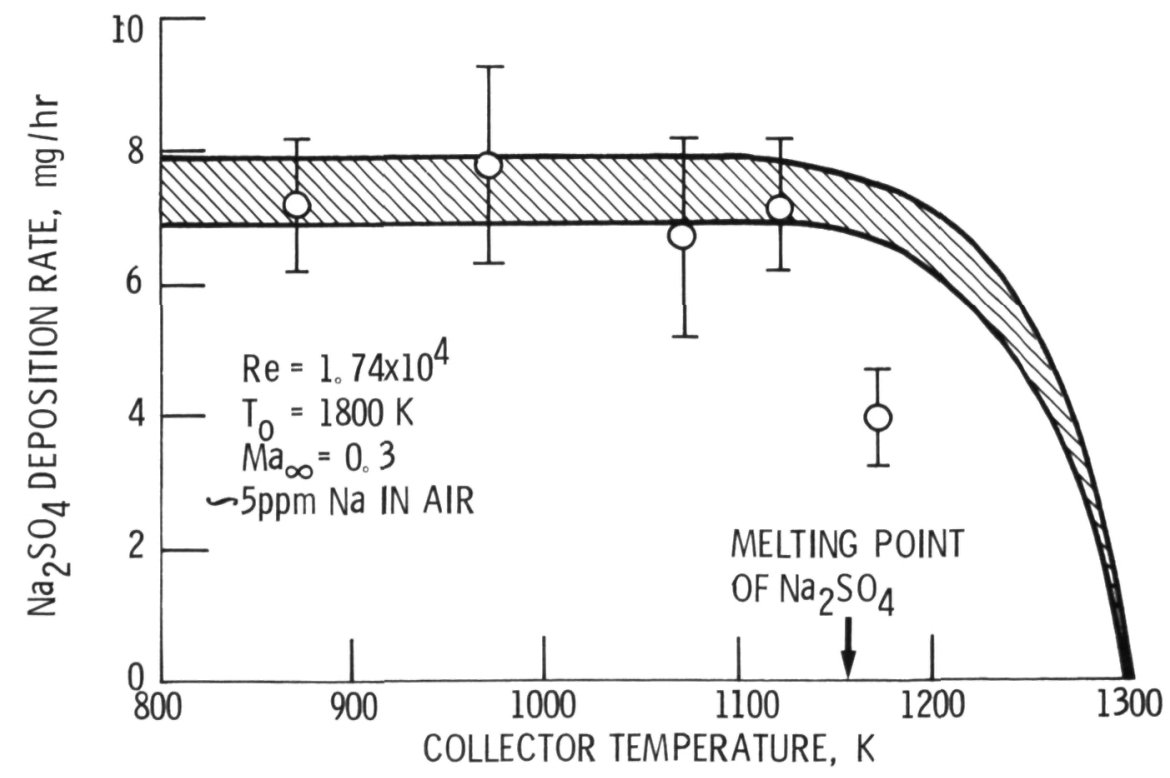

Figure 8. - Comparison of predicted and experimental sodium sulfate deposition rates for burner rigs. 




Figure 9. - Modification of figure by "Gokoğlu and Rosner (14). The symbols represent polar integration of experimental heat/mass transfer data from eight sources as in the original figure, but the curve was generated from $\mathrm{Eq}$ 。(7) and (8) of this report。 


\begin{tabular}{|c|c|c|c|c|}
\hline $\begin{array}{l}\text { 1. Report No. } \\
\text { NASA TM-87196 }\end{array}$ & \multicolumn{2}{|c|}{ 2. Government Accession No. } & \multicolumn{2}{|c|}{ 3. Recipient's Catalog No. } \\
\hline \multirow{2}{*}{\multicolumn{3}{|c|}{$\begin{array}{l}\text { 4. Title and Subtitle } \\
\text { Experiments for the Determination of Convective } \\
\text { Diffusion Heat/Mass Transfer to Burner Rig Test } \\
\text { Targets Comparable in Size to Jet Stream Diameter }\end{array}$}} & \multicolumn{2}{|l|}{ 5. Report Date } \\
\hline & & & \multicolumn{2}{|c|}{$\begin{array}{l}\text { 6. Performing Organization Code } \\
505-63-01\end{array}$} \\
\hline \multirow{2}{*}{\multicolumn{3}{|c|}{$\begin{array}{l}\text { 7. Author(s) } \\
\text { Gilbert J. Santoro and Süleyman A. Gökoğlu }\end{array}$}} & \multicolumn{2}{|c|}{$\begin{array}{l}\text { 8. Performing Organization Report No. } \\
\text { E-2794 }\end{array}$} \\
\hline & & & \multicolumn{2}{|l|}{ 10. Work Unit No. } \\
\hline \multirow{2}{*}{\multicolumn{3}{|c|}{$\begin{array}{l}\text { 9. Performing Organization Name and Address } \\
\text { National Aeronautics and Space Administration } \\
\text { Lewis Research Center } \\
\text { Cleveland, Ohio } 44135\end{array}$}} & \multirow{2}{*}{\multicolumn{2}{|c|}{ 11. Contract or Grant No. }} \\
\hline & & & & \\
\hline \multirow{2}{*}{\multicolumn{3}{|c|}{$\begin{array}{l}\text { 12. Sponsoring Agency Name and Address } \\
\text { National Aeronautics and Space Administration } \\
\text { Washington, D.C. } 20546\end{array}$}} & \multicolumn{2}{|c|}{$\begin{array}{l}\text { 13. Type of Report and Period Covered } \\
\text { Technical Memorandum }\end{array}$} \\
\hline & & & \multicolumn{2}{|c|}{ 14. Sponsoring Agency Code } \\
\hline \multicolumn{5}{|c|}{$\begin{array}{l}\text { 15. Supplementary Notes } \\
\text { Gilbert J. Santoro, NASA Lewis Research Center; Süleyman A. Gökoğlu, Case Western } \\
\text { Reserve University, Dept. of Mechanical and Aerospace Engineering, Cleveland, } \\
\text { Ohio } 44106 \text { and NASA Resident Research Associate. Prepared for the } 1986 \text { Winter } \\
\text { Annual Meeting of the American Society of Mechanical Engineers, Anaheim, } \\
\text { California, November } 30 \text { - December 5, } 1986 \text {. }\end{array}$} \\
\hline \multicolumn{5}{|c|}{$\begin{array}{l}\text { 16. Abstract } \\
\text { The application of a recently formulated vapor transport theory to predict dep- } \\
\text { osition rates of corrosive salts from alkali-seeded combustion gases of a small- } \\
\text { capacity, high-velocity, atmospheric-pressure burner rig was hampered by the } \\
\text { relatively large dimensions of the cylindrical deposit collector compared to the } \\
\text { diameter of the combustion gas stream. The relative dimensions lead to a highly } \\
\text { nonadiabatic combustion gas flow around the collector and necessitated two series } \\
\text { of experiments. In the first series, mass transfer coefficients were determined } \\
\text { by utilizing the naphthalene sublimation technique. The second series of experi- } \\
\text { ments determined the dilution effect on the sodium species concentrations due to } \\
\text { the entrainment of ambient air. This second series involved the measurement of } \\
\text { the temperature variation along the surface of the collector under steady state } \\
\text { conditions. Vapor deposition rates were determined exploiting this information } \\
\text { and the results were found to compare favorably with experimentally obtained } \\
\text { rates. }\end{array}$} \\
\hline \multirow{2}{*}{\multicolumn{2}{|c|}{$\begin{array}{l}\text { 17. Key Words (Suggested by Author(s)) } \\
\text { Deposition; Mass and heat transfer; } \\
\text { Boundary layer; Hot corrosion; Fouling; } \\
\text { Combustion }\end{array}$}} & \multirow{2}{*}{\multicolumn{3}{|c|}{$\begin{array}{l}\text { 18. Distribution Statement } \\
\text { Unclassified - unlimited } \\
\text { STAR Category } 34\end{array}$}} \\
\hline & & & & \\
\hline $\begin{array}{l}\text { 19. Security Classif. (of this report) } \\
\text { Unc lass if ied }\end{array}$ & $\begin{array}{r}\text { Security Classif. (of } \\
\text { Unc } 10\end{array}$ & $\begin{array}{l}\text { page) } \\
\text { ified }\end{array}$ & 21. No. of pages & 22. Price* \\
\hline
\end{tabular}


National Aeronautics and

Space Administration

\section{Lewis Research Center}

Cleveland. Ohio 44135

\section{Official Business}

Penalty for Private Use $\$ 300$
SECOND CLASS MAIL

ADDRESS CORRECTION REQUESTED

Postage and Fees Paid National Aeronautics and Space Administration NASA-451 